\title{
3 Research Square \\ Early Child Stimulation, Linear Growth and Neurodevelopment in Low Birth Weight Infants
}

Ravi Prakash Upadhyay ( $\square$ ravi.p.upadhyay@sas.org.in )

Society for Applied Studies

\section{Sunita Taneja}

Society for Applied Studies

\section{Tor Arne Strand}

Innlandet Hospital Trust

Halvor Sommerfelt

University of Bergen

Mari Hysing

University of Bergen

Sarmila Mazumder

Society for Applied Studies

Nita Bhandari

Society for Applied Studies

Jose Martines

University of Bergen

Tarun Dua

World Health Organization

Patricia Kariger

University of California

Rajiv Bahl

World Health Organization

\section{Research Article}

Keywords: Linear growth, Child stimulation, Neurodevelopment, Low birth weight, Infancy

Posted Date: January 27th, 2022

DOI: https://doi.org/10.21203/rs.3.rs-1176924/v1

License: (9) This work is licensed under a Creative Commons Attribution 4.0 International License.

Read Full License 


\section{Abstract \\ Background}

Children with low birth weight (LBW) are at risk of linear growth faltering and developmental deficits. Evidence suggests that early child stimulation and care reflected as responsive caregiving and opportunities for learning can promote development. The current analysis aimed to measure the extent to which linear growth and early child stimulation modify each other's association with neurodevelopmental outcomes among LBW infants.

\section{Methods}

This is a secondary data analyses from a randomized controlled trial on the effect of community-initiated kangaroo mother care in LBW infants on their neurodevelopment at 12 months of corrected age. Bayley Scales of Infant and Toddler Development was used to assess cognitive, motor and language scores. Stimulation at home was assessed by the Pediatric Review of Children's Environmental Support and Stimulation (PROCESS) tool. PROCESS scores were categorized into three groups: < Mean-1SD (Iow stimulation); Mean \pm 1 SD (moderate stimulation) and > mean + 1SD (high stimulation).

\section{Results}

A total of 516 infants were available for neurodevelopment assessments. Interactions were observed between length for age z-score (LAZ) and PROCESS score categories. In the low stimulation group, the adjusted regression coefficients for the association between LAZ and cognitive, motor and language scores were substantially higher than in the moderate and high stimulation group. Stimulation was positively associated with neurodevelopmental outcomes in both stunted and non-stunted infants; however, the association was twice as strong in stunted than in non-stunted.

\section{Conclusion}

Moderate to high quality stimulation may alleviate the risk of sub-optimal development in LBW infants with linear growth deficits

\section{Clinical Trial Registration:}

The primary trial whose data are analysed is registered at clinicaltrials.gov (https://clinicaltrials.gov/ct2/show/NCT02631343)

\section{What Is Already Known On This Topic?}


- Linear growth and quality of stimulation and nurturance are independently known to influence neurodevelopment, especially in children born with low birth weight (LBW).

- The extent to which they influence each other's association with cognitive, motor and language scores is unknown.

\section{What this study adds?}

- High quality stimulation and nurturance could protect LBW infants with growth deficits from poor development scores.

- Association of stimulation with neurodevelopmental outcomes was twice as strong in stunted than in non-stunted infants.

\section{Introduction}

The first 1000 days i.e., from conception through age 24 months, are foundational for brain development [1]. Both adverse and positive experiences during this period may critically shape children's developmental trajectories [2,3]. Children born with low birth weight (LBW) are at risk of linear growth faltering, cognitive and motor deficits as well as lower academic performance and behavioural problems compared to their normal birth weight counterparts [4-7]. Linear growth faltering in the first 2 years of life has been shown to be negatively associated with cognitive performance in childhood $[8,9]$. There is also strong evidence that a child's positive home environment reflected as responsive caregiving and opportunities for early learning, can promote development [10-12].

Less is known on whether linear growth and quality of stimulation/responsive caregiving at home influence each other's association with cognitive, motor and language scores. Using a sample of 513 infants from rural India, Black et al. showed that a nurturant home environment attenuated associations between linear growth and fine motor and receptive language development [13]. Similarly, another study from rural Vietnam did not detect significant associations between linear growth and child development in the context of a high-quality home environment [14]. These findings indicate that in the presence of an environment characterized by nurturance and learning opportunities, children with low length-for- age $z$ score (LAZ) can acquire developmental skills at the same level as their peers. Contrasting these findings, recent studies from Malaysian and Jamaican infants found no significant influence of home environment quality on the association between LAZ status and cognitive outcomes $[15,16]$. More evidence is required on the interactive effects of linear growth and home environment in relation to developmental outcomes, particularly for the vulnerable subset of LBW infants. Further, evidence is required on whether in a setting with socio-economic constraints, a moderate to high-quality home environment can protect LBW infants with growth deficits from poor development scores and whether there is a differential effect of stimulation on developmental outcomes based on whether the LBW infant is stunted or not. The present analysis was aimed at providing insights on these pertinent issues of global importance. 


\section{Methods}

\section{Study design and participants}

This secondary data analysis was conducted using data from an individually randomized controlled trial (RCT) aimed to evaluate the effect of community-initiated Kangaroo Mother Care (ciKMC) on neurodevelopmental outcomes of infants born low birth weight at 12 months of corrected age (ClinicalTrials.gov identifier NCT02631343) [17]. The study was conducted in resource constrained settings of rural and semi-urban Haryana, North India. In this study population, ciKMC was not associated with the neurodevelopment measures at 12 months [17]. A total of 552 stable preterm or small for gestational age term infants identified within 72 hours of birth and weighing between 1500 and $2250 \mathrm{~g}$ were included in the trial and followed up till 12 months of age. Details of the trial have been published elsewhere $[17,18]$. Ethical clearances for the primary trial were obtained from the Institutional Ethics Review Committee of Society for Applied Studies, New Delhi (SAS/ERC/KMC-GCC/2015), the World Health Organization (WHO) Ethics Review Committee, Geneva (ERC0002629) and the Regional Committee for Medical and Health Research Ethics in Norway. In the primary trial, written informed consent was obtained from all subjects and/or their legal guardian(s).

\section{Exposure and outcomes}

Baseline information was collected on maternal and paternal age and education, birth order, parity and sex of the infant. Gestational age was documented from an ultrasound report, hospital records or maternal recall, whichever was available, in the given order of preference. The wealth of the family was determined by an index created through a principal component analysis based on household assets [19]. Information on vital status, illnesses (including any hospitalization) along with anthropometric measurements (weight and length) were captured by an independent trained team during their home visits at infant age 1, 3, 6 and 12 months. Caregivers were asked about illness(es) and hospitalization(s) in the 2 weeks preceding the visit. Length was measured using infantometers reading to the nearest 0.1 $\mathrm{cm}$. Exclusivity of breastfeeding was assessed at 1, 3 and 6 months of infant age through a structured questionnaire.

Developmental outcomes were ascertained in the study clinic by trained psychologists using the Bayley Scales of Infant and Toddler Development, 3rd Edition (BSID-III) at 12 months of corrected age [20]. The BSID-III was adapted for use in the study setting. Details of the adaptation have been provided elsewhere [17]. Child stimulation at home was assessed at 12 months of age by trained psychologists using "Pediatric Review of Children's Environmental Support and Stimulation (PROCESS)" questionnaire [2123]. PROCESS was created for use with parents of children 2-18 months of age and can be administered in a clinic or in a home setting [21]. It consists of three components: a parent questionnaire, clinical observation, and a toy checklist. The parent questionnaire includes 24 items about the physical environment, household organization, and stimulation practices for development. The 20 observational items focus primarily on the emotional quality of parent-child interactions and the toy checklist consists of 40 items. Total scores are summed across the three sections [21]. Higher scores reflect better 
stimulation and support to infants. PROCESS scores have been shown to have a good correlation $(r=0.84)$ with the most widely used measure of the household environment i.e., Home Observation for Measurement of the Environment (HOME) scores [22, 23].

\section{Plan of analyses}

All analyses were done using STATA version 16.0 and R version 3.3.3 (2017-03-06). Baseline characteristics were summarized as mean (SD) or proportion. Length-for-age z score (LAZ) was calculated based on the WHO Child Growth Standards [24]. Stunting was defined as LAZ <-2, based on the standard WHO definition. ${ }^{24}$ PROCESS scores, reflecting stimulation environment at home, were categorized into three groups: Low stimulation group (< Mean-1SD); moderate stimulation group (Mean \pm 1 SD) and high stimulation group (> Mean + 1SD). The mean (SD) PROCESS score was 124 (17).

Neurodevelopmental outcomes consisted of cognitive, motor and language composite scores assessed by BSID-III at 12 months of corrected age. We first measured the association of LAZ at 6 months and PROCESS scores with scores obtained on BSID-III. We selected covariates for adjustment in the model based on their biological plausibility to influence the exposure and the outcomes and purposive selection principle i.e., covariates that brought at least $15 \%$ change in the univariate beta-coefficient were included in the multivariable model $[25,26]$.

We assessed the interaction between LAZ scores at 6 months of age and the PROCESS scores using likelihood ratio test comparing models with and without interaction terms. Analyses were stratified following the identification of a possible interaction. We initially did a screening where a P-value for interaction of less than 0.20 was investigated further [27]. The investigation was focussed on examining whether the magnitude of association between LAZ and outcome(s) of interest differed between the subgroups based on PROCESS score categories. Stratified results were presented at differing levels of PROCESS scores (low, moderate and high stimulation). For each of the categories of PROCESS score, we used linear regression with the composite scores for cognition, motor or language as an outcome and LAZ score as the exposure variable. Selection of variables for adjustment in the models was based on biological plausibility and purposive selection principle $[25,26]$.

Similarly, to assess whether the association between PROCESS scores and neurodevelopmental outcomes was modified by whether the babies were stunted or not, the interaction between the PROCESS score categories and stunting status was assessed using likelihood ratio test comparing models with and without interaction terms. In instances where the P-value of interaction was less than 0.20 , the analyses were stratified and the effect sizes for the association between PROCESS categories and outcome(s) of interest were presented by the stunting categories. We used generalized additive models (GAM) in the mgcv package in R statistical package to depict non-linear associations between PROCESS score, LAZ and outcome scores (composite cognitive, motor and language scores) [28].

\section{Ethics approval}


No ethical approval was required for this secondary data analysis. However, the authors obtained written permission from the principal investigator of the primary trial to use the data for this secondary analysis.

\section{Results}

\section{Characteristics of the sample}

Baseline characteristics of the 516 infants included in this analysis have been presented in Table 1. The mean (SD) composite cognitive, motor and language scores of the sample were 102.1 (11.8), 90.2 (10.4) and 84.9 (9.1) respectively. A total of $52.5 \%(271 / 516)$ of the infants were stunted at 6 months of age. 
Table 1

Baseline characteristics of the infants included in this secondary data analysis ( $N=516)$

Variables

Number (\%)

HOUSEHOLD CHARACTERISTICS

Yearly family income (in USD); Median (IQR)

$1316(948-2368)$

Proportion of families below poverty line

$122(23.7)$

Religion

$423(81.9)$

Hindu

$89(17.3)$

Muslim

$4(0.8)$

Others $^{\text {a }}$

Social $_{\text {class }}{ }^{b}$

$133(25.8)$

General

$167(32.4)$

Other Backward Class (OBC)

$216(41.8)$

Scheduled Caste/Tribe (SC/ST)

Type of family

$135(26.2)$

Nuclear

$381(73.8)$

Joint

\title{
MATERNAL AND PATERNAL CHARACTERISTICS
}

Mean maternal age (years; SD)

Median years of education of mother (IQR)

$5(0-9)$

Mother's occupation $507(98.3)$

Home maker

Mean father's age (years; SD)

$26.4(4.7)$

Median years of education of father (IQR)

$8(5-12)$

\section{BIRTH RELATED CHARACTERISTICS}

\begin{abstract}
a Others: Christian/Sikh/Jain/Parsi/Zoroastrian/Buddhist/neo Buddhist; ${ }^{\text {b }}$ General- group that do not qualify for any of the positive discrimination schemes by Government of India (GOI), OBC- term used by the Government of India to classify castes which are socially and educationally disadvantaged, SC/ST- official designations given to groups of historically disadvantaged indigenous people in India; USD- United States Dollar; SD- standard deviation; IQR- Inter-quartile range
\end{abstract}




\begin{tabular}{|c|c|}
\hline Variables & Number (\%) \\
\hline Place of delivery & $148(28.7)$ \\
\hline Home & $266(51.5)$ \\
\hline Government facility & $102(19.8)$ \\
\hline \multicolumn{2}{|l|}{ Private facility } \\
\hline Type of delivery & $511(99.0)$ \\
\hline \multicolumn{2}{|l|}{ Normal } \\
\hline Birth order & $191(37.0)$ \\
\hline 1 & $232(45.0)$ \\
\hline $2-3$ & $93(18.0)$ \\
\hline \multicolumn{2}{|l|}{$\geq 4$} \\
\hline Parity & $191(37.0)$ \\
\hline \multicolumn{2}{|l|}{ Primiparous } \\
\hline \multicolumn{2}{|l|}{ INFANT CHARACTERISTICS } \\
\hline Sex of the baby & $208(40.3)$ \\
\hline \multicolumn{2}{|l|}{ Male } \\
\hline Mean birth weight (grams, SD) & $2058.7(165.3)$ \\
\hline Birth weight (range; in grams) & $1550-2250$ \\
\hline Mean gestational age (weeks, SD) & $35.7(1.9)$ \\
\hline Gestational age (range; in weeks) & $24-40$ \\
\hline Early initiation of breastfeeding (within an hour of birth) present & $323(62.6)$ \\
\hline Exclusive breastfeeding at 3 months & $250(48.4)$ \\
\hline \multicolumn{2}{|c|}{$\begin{array}{l}\text { a Others: Christian/Sikh/Jain/Parsi/Zoroastrian/Buddhist/neo Buddhist; }{ }^{\text {b }} \text { General- group that do not } \\
\text { qualify for any of the positive discrimination schemes by Government of India (GOI), OBC- term used } \\
\text { by the Government of India to classify castes which are socially and educationally disadvantaged, } \\
\text { SC/ST- official designations given to groups of historically disadvantaged indigenous people in India; } \\
\text { USD- United States Dollar; SD- standard deviation; IQR-Inter-quartile range }\end{array}$} \\
\hline
\end{tabular}

\section{LAZ, PROCESS score and cognitive outcome}

LAZ and PROCESS scores were associated with cognitive scores (Table 2). 
Table 2

Association of length for age $z$ score (LAZ) and PROCESS score with cognitive, motor and language scores at 12 months of corrected age $(\mathrm{N}=516)$

\begin{tabular}{|c|c|c|c|}
\hline \multirow[t]{2}{*}{ Variables } & Cognitive score & Motor score & Language score \\
\hline & \multicolumn{3}{|c|}{ Adjusted mean difference, $b(95 \% \mathrm{Cl}){ }^{a}$; p value } \\
\hline LAZ at 6 months & $\begin{array}{l}1.78(0.74,2.83) \\
p=0.001\end{array}$ & $\begin{array}{l}2.02(1.11,2.94) \\
p<0.001\end{array}$ & $\begin{array}{l}1.15(0.37,1.93) \\
p=0.004\end{array}$ \\
\hline \multirow{2}{*}{$\begin{array}{l}\text { Stunting status at } 6 \\
\text { months } \\
\text { Non-stunted }\end{array}$} & Ref & Ref & Ref \\
\hline & $\begin{array}{l}-2.99(-5.11,-0.87) \\
p=0.006\end{array}$ & $\begin{array}{l}-3.42(-5.28,-1.55) \\
p<0.001\end{array}$ & $\begin{array}{l}-2.53(-4.11,-0.95) \\
p=0.002\end{array}$ \\
\hline \multicolumn{4}{|l|}{ Stunted } \\
\hline $\begin{array}{l}\text { PROCESS score at } 12 \\
\text { months }\end{array}$ & $\begin{array}{l}0.25(0.18,0.31) \\
p<0.001\end{array}$ & $\begin{array}{l}0.16(0.10,0.22) \\
p<0.001\end{array}$ & $\begin{array}{l}0.22(0.17,0.27) \\
p<0.001\end{array}$ \\
\hline PROCESS categories & Ref & Ref & Ref \\
\hline$<$ Mean-1 SD (Low) & $\begin{array}{l}9.52(6.47,12.56) \\
p<0.001\end{array}$ & $\begin{array}{l}6.60(3.85,9.36) \\
p<0.001\end{array}$ & $\begin{array}{l}7.76(5.53,9.99) \\
p<0.001\end{array}$ \\
\hline $\begin{array}{l}\text { Mean } \pm 1 \text { SD (Moderate) } \\
>\text { Mean+1SD (High) }\end{array}$ & $\begin{array}{l}12.94(8.95,16.95) \\
p<0.001\end{array}$ & $\begin{array}{l}8.60(4.98,12.23) \\
p<0.001\end{array}$ & $\begin{array}{l}11.82(8.89,14.76) \\
p<0.001\end{array}$ \\
\hline
\end{tabular}

There was an interaction between LAZ and PROCESS score categories for the cognitive composite score $(P=0.08)$ (Table 3). 
Table 3

Association between length for age z score and neurodevelopmental outcomes, by PROCESS score categories

\section{Variable $\quad \mathrm{N}=516$}

Adjusted regression coefficient (b) ${ }^{a}$

$95 \% \mathrm{Cl}$

P-value

\section{Cognitive composite score}

(P-value for interaction between PROCESS score categories and LAZ score $=0.08$ )

In low stimulation group $(\mathrm{n}=72)$
LAZ score
3.63
$1.22,6.03$
0.004

In moderate stimulation group $(n=367)$
LAZ score
1.41
$0.25,2.56$
0.02

In high stimulation group $(\mathrm{n}=77)$
LAZ score
1.69
$-1.15,4.52$
0.24

\section{Motor composite score}

(P-value for interaction between PROCESS score categories and LAZ score=0.03)

In low stimulation group $(\mathrm{n}=72)$
LAZ score
4.08
$1.69,6.46$
0.001

In moderate stimulation group $(\mathrm{n}=367)$
LAZ score
1.54
$0.50,2.58$
0.004

In high stimulation group $(\mathrm{n}=77)$
LAZ score
1.05
$-1.14,3.25$
0.34

\section{Language composite score}

( $P$-value for interaction between PROCESS score categories and LAZ score=0.12)

In Low stimulation group $(\mathrm{n}=72)$
LAZ score
2.47
$0.56,4.38$
0.01

In moderate stimulation group $(\mathrm{n}=367)$

\footnotetext{
a Adjusted for wealth quintile, maternal age, maternal education, father's age, father's education, parity, birth order, sex of the infant, gestational age, exclusive breastfeeding at 3 months, study groups (intervention and control) and hospitalization for severe illness during infancy; Low stimulation group (PROCESS score; < Mean-1SD); moderate stimulation group (PROCESS score; Mean \pm 1 SD) and high stimulation group (PROCESS score; > Mean + 1SD); LAZ- Length for age Z score; PROCESS- Pediatric Review of Children's Environmental Support and Stimulation; SD- Standard Deviation
} 


\begin{tabular}{|c|c|c|c|}
\hline \multirow[t]{2}{*}{ Variable } & \multicolumn{3}{|l|}{$\mathrm{N}=516$} \\
\hline & Adjusted regression coefficient (b) ${ }^{a}$ & $95 \% \mathrm{Cl}$ & P-value \\
\hline LAZ score & 1.02 & $0.21,1.86$ & 0.02 \\
\hline \multicolumn{4}{|c|}{ In high stimulation group $(\mathrm{n}=77)$} \\
\hline LAZ score & 0.40 & $-1.78,2.58$ & 0.72 \\
\hline \multicolumn{4}{|c|}{$\begin{array}{l}\text { a Adjusted for wealth quintile, maternal age, maternal education, father's age, father's education, } \\
\text { parity, birth order, sex of the infant, gestational age, exclusive breastfeeding at } 3 \text { months, study groups } \\
\text { (intervention and control) and hospitalization for severe illness during infancy; Low stimulation group } \\
\text { (PROCESS score; < Mean-1SD); moderate stimulation group (PROCESS score; Mean } \pm 1 \text { SD) and high } \\
\text { stimulation group (PROCESS score; > Mean + 1SD); LAZ-Length for age Z score; PROCESS- Pediatric } \\
\text { Review of Children's Environmental Support and Stimulation; SD- Standard Deviation }\end{array}$} \\
\hline
\end{tabular}

In the low stimulation group, the adjusted regression coefficient $(b=3.63,95 \% \mathrm{Cl} ; 1.22,6.03)$ was substantially higher than in the moderate stimulation group $(b=1.41,95 \% \mathrm{Cl} ; 0.25,2.56)$ and the high stimulation group ( $b=1.69,95 \% \mathrm{Cl} ;-1.15,4.52)$ (Table 3 ). The GAM plot supports the findings obtained in regression models (Figure 1). An interaction was observed between stunting and PROCESS score categories (Table 4). 
Table 4

Association between PROCESS score categories and neurodevelopmental outcomes, by stunting status

Variable

$\mathrm{N}=516$

Adjusted regression coefficient (b) ${ }^{a}$

$95 \% \mathrm{Cl}$

P-value

Cognitive composite score

(P-value for interaction between PROCESS score categories and stunting categories $=0.17$ )

LAZ $<-2(n=271)$

Low stimulation

Ref

$7.26,14.92$

$<0.001$

Moderate stimulation

11.09

$9.66,20.68$

$<0.001$

High stimulation

15.17

$L A Z \geq-2(n=245)$

Low stimulation

Ref

$1.77,10.97$

0.007

Moderate stimulation

6.37

$3.54,15.08$

0.002

High stimulation

9.31

\section{Motor composite score}

(P-value for interaction between PROCESS score categories and stunting categories $=0.12$ )

LAZ $<-2(n=271)$

Low stimulation

Ref

$4.49,11.88$

$<0.001$

Moderate stimulation

8.19

$6.44,17.06$

$<0.001$

High stimulation

11.76

$L A Z \geq-2(n=245)$

Low stimulation

Ref

$-0.53,7.09$

0.09

Moderate stimulation

3.28

$-0.54,9.03$

0.08

High stimulation

4.24

\section{Language composite score}

(P-value for interaction between PROCESS score categories and stunting categories $=0.05$ )

a Adjusted for wealth quintile, maternal age, maternal education, father's age, father's education, parity, birth order, sex of the infant, gestational age, exclusive breastfeeding at 3 months, study groups (intervention and control) and hospitalization for severe illness during infancy; Low stimulation (PROCESS score; < Mean-1SD); moderate stimulation (PROCESS score; Mean \pm 1 SD) and high stimulation (PROCESS score; > Mean + 1SD); LAZ- Length for age Z score; PROCESS- Pediatric Review of Children's Environmental Support and Stimulation; SD- Standard Deviation 


\begin{tabular}{|c|c|c|c|}
\hline \multirow[t]{2}{*}{ Variable } & \multicolumn{3}{|l|}{$\mathrm{N}=516$} \\
\hline & Adjusted regression coefficient (b) ${ }^{a}$ & $95 \% \mathrm{Cl}$ & P-value \\
\hline \multicolumn{4}{|l|}{ LAZ $<-2(n=271)$} \\
\hline Low stimulation & Ref & $6.58,11.95$ & $<0.001$ \\
\hline Moderate stimulation & 9.26 & $10.32,18.05$ & $<0.001$ \\
\hline High stimulation & 14.19 & & \\
\hline \multicolumn{4}{|l|}{$L A Z \geq-2(n=245)$} \\
\hline Low stimulation & Ref & $0.82,7.75$ & 0.02 \\
\hline Moderate stimulation & 4.29 & $3.13,11.83$ & 0.001 \\
\hline High stimulation & 7.48 & & \\
\hline \multicolumn{4}{|c|}{$\begin{array}{l}\text { a Adjusted for wealth quintile, maternal age, maternal education, father's age, father's education, } \\
\text { parity, birth order, sex of the infant, gestational age, exclusive breastfeeding at } 3 \text { months, study groups } \\
\text { (intervention and control) and hospitalization for severe illness during infancy; Low stimulation } \\
\text { (PROCESS score; < Mean-1SD); moderate stimulation (PROCESS score; Mean } \pm 1 \text { SD) and high } \\
\text { stimulation (PROCESS score; > Mean + 1SD); LAZ- Length for age Z score; PROCESS- Pediatric } \\
\text { Review of Children's Environmental Support and Stimulation; SD- Standard Deviation }\end{array}$} \\
\hline
\end{tabular}

In both stunted and non-stunted infants, PROCESS scores were associated with cognitive scores with a clear dose response relationship (Table 4). The adjusted regression coefficient was comparatively higher in stunted infants.

\section{LAZ, PROCESS score and motor outcome}

LAZ and PROCESS scores were associated with motor scores (Table 2). There was an interaction between LAZ and PROCESS score categories for the motor composite score $(P=0.03)$ (Table 3$)$. In the low stimulation group, the adjusted regression coefficient $(b=4.08,95 \% \mathrm{Cl} ; 1.69,6.46)$ was higher than in the moderate stimulation $(b=1.54,95 \% \mathrm{Cl} ; 0.50,2.58)$ and the high stimulation group ( $b=1.05,95 \% \mathrm{Cl} ;-1.14$, 3.25) (Table 3). The GAM plot confirmed the findings obtained in regression models (Figure 1). An interaction was observed between stunting and PROCESS score categories (Table 4). In stunted infants, PROCESS scores were associated with motor composite scores with a dose response relationship. In nonstunted infants, the adjusted regression coefficient was comparatively lower and did not reach statistical significance.

\section{LAZ, PROCESS score and language outcome}

LAZ and PROCESS scores were associated with language scores (Table 2). A potentially relevant interaction ( $P=0.12$ ) was observed between LAZ and PROCESS score categories (Table 3 ). In the low stimulation group, the adjusted regression coefficient $(b=2.47,95 \% \mathrm{Cl} ; 0.56,4.38)$ was substantially higher than in the moderate stimulation $(b=1.02,95 \% \mathrm{Cl} ; 0.21,1.86)$ and high stimulation group $(b=0.40$, 
$95 \% \mathrm{Cl} ;-1.78,2.58$ ) (Table 3). The GAM plot confirmed the findings obtained in regression models (Figure 1). An interaction was observed between stunting and PROCESS score categories ( $P=0.05)$ (Table 4$)$. In both stunted and non-stunted infants, PROCESS scores were associated with language scores with a distinct dose response relationship. The adjusted regression coefficient was comparatively higher in stunted infants.

\section{Discussion}

The current analyses aimed at providing answers to questions with programmatic implications, specifically whether within a setting with socio-economic constraints, a moderate to high-quality home environment can alleviate the risk of low development scores in LBW infants with linear growth deficits. We observed that with increase in stimulation and nurturance at home, the association between linear growth and neurodevelopmental outcomes weakened. Additionally, we also observed that while stimulation at home was associated with neurodevelopmental outcomes in both stunted and non-stunted infants, the association was stronger in stunted than non-stunted infants.

Our findings corroborate the studies done in Bangladesh and Vietnam where the authors noted that among non-low birth weight children, a nurturant home environment attenuated the association between linear growth and neurodevelopmental outcomes $[13,14]$. However, findings contrast with the results of the studies among the Malaysian and Jamaican children where no significant influence of home environment quality on the association between LAZ status and cognitive outcomes was noted. The observed difference might be due to fairly smaller sample sizes in these studies, thereby reducing the power to detect significant interactions $[15,16]$.

There is lack of consensus with regards to the consideration of P-value to indicate presence of an interaction. While some investigators propose to adhere to the conventional P-value of $<0.05$, others suggest that usually the power to test for interactions is low in many epidemiologic studies and therefore, testing for interaction tests based solely on P-value of $<0.05$ may be misleading and could probably miss out important effect modifications [27, 29-31]. Based on this consideration, the suggestion is to increase the type 1 error rate to $20 \%$ while assessing tests of interaction [27]. Some researchers argue that consideration of a P-value for interaction tests is a part of the entire spectrum of information to be utilized in the assessment of effect modification and other components should be considered such as stratum-specific measures and prior biological knowledge [32, 33]. In our study, we considered a P-value of less than 0.20 to further investigate for potential interaction. Subsequently, we placed emphasis on the magnitude of effect size within the subgroups and attempted to make careful interpretations. Our findings were also supported by the GAM plots that depicted non-linear relationships between LAZ, PROCESS score and neurodevelopment outcomes.

There are strengths and limitations of this secondary data analyses. The data utilized is from a robust and well conducted randomized controlled trial with very low attrition. The measurements, including the anthropometry, and outcome data were collected by trained and standardized study team. One of the 
limitations is that the study lacks reliable data on gestational age. Weight was measured within 72 hours of birth by trained study team and inclusion of infants with weight between $1500-2250 \mathrm{~g}$ meant that these infants would be either preterm or term small for gestational age. Therefore, the findings could be extended only to a specific population of LBW infants i.e., stable late preterm or term small for gestational age (SGA) infants. There could also be a possibility that in babies with poorer linear growth or smaller attained length at 6 months of age or rather the factors that lead to such growth faltering may lead to poorer home stimulation which is measured 6 months later by PROCESS. Measurement of home stimulation at one time point only i.e., at 12 months is also a limitation. We also acknowledge that this being an observational study, the results may be affected by unmeasured confounding.

Our findings support the promotion of stimulation to LBW infants in order to offset the negative effect of growth faltering on neurodevelopmental outcomes. While such intervention should be provided to all infants, this should particularly be directed to LBW infants and among them, to those with linear growth deficits. Our findings indicate that through focusing only on nutrition for growth, we may miss to capitalize the important developmental effects of early child stimulation and responsive caregiving. The findings call for a comprehensive approach with nutrition and nurturing care at the forefront. This approach underlies the comprehensive framework of Nurturing Care that incorporates health, nutrition, responsive caregiving, opportunities for early learning, and child protection as a way to help children not only survive but also thrive [34].

\section{Conclusion}

The findings suggest that a moderate to high-quality stimulation at home may alleviate the risk of poor development scores in LBW infants with linear growth deficits. Early child stimulation may particularly be beneficial for LBW infants with linear growth deficits/stunting. Efforts for improving child development should be comprehensive with promotion of adequate nutrition and optimal nurturing care as integral components.

\section{Abbreviations}

LBW- Low birth weight

PROCESS- Pediatric Review of Children's Environmental Support and Stimulation tool

LAZ- Length for age $Z$ score

RCT- Randomized controlled trial

CiKMC- Community initiated Kangaroo Mother Care

HBPNC- Home Based Post Natal Care

BSID-III - Bayley Scales of Infant and Toddler Development, $3^{\text {rd }}$ Edition 
HOME- Home Observation for Measurement of the Environment

GAM- Generalized additive models

SGA-Small for gestational age

AGA- Appropriate for gestational age

\section{Declarations}

\section{Ethics approval and consent to participate}

No ethical approval was required for this secondary data analysis. Ethical clearances for the primary trial were obtained from the Institutional Ethics Review Committee of Society for Applied Studies, New Delhi, the World Health Organization (WHO) Ethics Review Committee, Geneva and the Regional Committee for Medical and Health Research Ethics in Norway.

\section{Consent for publication}

Not applicable

\section{Availability of data and materials}

The dataset analysed in the present study is publicly available at: https://figshare.com/s/c932d11ff5101e2268bf

\section{Competing interests}

No competing interest to declare

Funding source: The original study on which the current manuscript is based was funded by Grand Challenges Canada (Grant Number 0725-03) and the Research Council of Norway (RCN) through its Centers of Excellence Scheme (project number 223269) and by the University of Bergen through funding to the Centre for Intervention Science in Maternal and Child Health (CISMAC). The funding agency had no role in the designing the study; the collection, analysis, and interpretation of data; the writing of the manuscript; and the decision to submit the paper for publication.

\section{Contributor's statement}

RPU, ST, TAS and MH were involved in conceptualization, data acquisition, analysis, interpretation of data and drafting of the manuscript.

ST, NB and SM were involved in designing and conducting the primary trial.

NB and SM also provided administrative and technical support for this secondary data analysis exercise. 
HS, JM, TD, PK and RB provided critical feedback on the statistical analysis and drafting of the manuscript.

All authors critically reviewed the manuscript, provided important intellectual content and approved the final manuscript as submitted. The authors agree to be accountable for all aspects of the work.

\section{Acknowledgment: None}

\section{References}

1. Fox SE, Levitt P, Nelson CA 3rd. How the timing and quality of early experiences influence the development of brain architecture. Child Dev. 2010;81(1):28-40.

2. Wachs TD, Georgieff M, Cusick S, McEwen BS. Issues in the timing of integrated early interventions: contributions from nutrition, neuroscience, and psychological research. Ann N Y Acad Sci. 2014;1308:89-106.

3. Bick J, Nelson CA. Early Adverse Experiences and the Developing Brain. Neuropsychopharmacology. 2016;41(1):177-196

4. Upadhyay RP, Naik G, Choudhary TS, Chowdhury R, Taneja S, Bhandari N, et al. Cognitive and motor outcomes in children born low birth weight: a systematic review and meta-analysis of studies from South Asia. BMC Pediatr. 2019;19(1):35.

5. Arpi E, Ferrari F. Preterm birth and behaviour problems in infants and preschool-age children: a review of the recent literature. Dev Med Child Neurol. 2013;55(9):788-96.

6. Weindrich D, Jennen-Steinmetz C, Laucht M, Schmidt MH. Late sequelae of low birthweight: mediators of poor school performance at 11 years. Dev Med Child Neurol. 2003;45(7):463-9.

7. Danaei G, Andrews KG, Sudfeld CR, Fink G, McCoy DC, Peet E, et al. Risk Factors for Childhood Stunting in 137 Developing Countries: A Comparative Risk Assessment Analysis at Global, Regional, and Country Levels. PLoS Med. 2016;13(11):e1002164.

8. Sudfeld CR, McCoy DC, Danaei G, Fink G, Ezzati M, Andrews KG, et al. Linear growth and child development in low- and middle-income countries: a meta-analysis. Pediatrics. 2015;135(5):e126675 .

9. Adair LS, Fall CH, Osmond C, Stein AD, Martorell R, Ramirez-Zea M, et al. Associations of linear growth and relative weight gain during early life with adult health and human capital in countries of low and middle income: findings from five birth cohort studies. Lancet. 2013;382(9891):525-34.

10. Hartinger SM, Lanata CF, Hattendorf J, Wolf J, Gil Al, Obando MO, et al. Impact of a child stimulation intervention on early child development in rural Peru: a cluster randomised trial using a reciprocal control design. J Epidemiol Community Health. 2017;71(3):217-224

11. Yousafzai AK, Obradović J, Rasheed MA, Rizvi A, Portilla XA, Tirado-Strayer N, et al. Effects of responsive stimulation and nutrition interventions on children's development and growth at age 4 
years in a disadvantaged population in Pakistan: a longitudinal follow-up of a cluster-randomised factorial effectiveness trial. Lancet Glob Health. 2016;4(8):e548-e558

12. Worku BN, Abessa TG, Wondafrash M, Lemmens J, Valy J, Bruckers L, et al. Effects of home-based play-assisted stimulation on developmental performances of children living in extreme poverty: a randomized single-blind controlled trial. BMC Pediatr. 2018;18(1):29. Published 2018 Feb 5. doi:10.1186/s12887-018-1023-0

13. Black MM, Yimgang DP, Hurley KM, Harding KB, Fernandez-Rao S, Balakrishna N, et al. Mechanisms linking height to early child development among infants and preschoolers in rural India. Dev Sci. 2019;22(5):e12806.

14. Nguyen PH, Headey D, Frongillo EA, Tran LM, Rawat R, Ruel MT, et al. Changes in underlying determinants explain rapid increases in child linear growth in Alive \& Thrive Study Areas between 2010 and 2014 in Bangladesh and Vietnam. J Nutr. 2017;147(3):462-469

15. Nurliyana AR, Mohd Shariff Z, Mohd Taib MN, Gan WY, Tan KA. Early growth and home environment are associated with cognitive development in the first year of life of Malaysian infants. Early Hum Dev. 2019;140:104890. [published online ahead of print, 2019 Oct 23]

16. Walker SP, Grantham-Mcgregor SM, Powell CA, Chang SM. Effects of growth restriction in early childhood on growth, IQ, and cognition at age 11 to 12 years and the benefits of nutritional supplementation and psychosocial stimulation. J Pediatr. 2000;137(1):36-41.

17. Taneja S, Sinha B, Upadhyay RP, Mazumder S, Sommerfelt H, Martines J, et al. Community initiated kangaroo mother care and early child development in low birth weight infants in India- A randomized controlled trial. BMC Pediatr 20, 150 (2020). https://doi.org/10.1186/s12887-020-02046-4

18. Mazumder S, Taneja S, Dube B, Bhatia K, Ghosh R, Shekhar M, et al. Effect of community-initiated kangaroo mother care on survival of infants with low birthweight: a randomised controlled trial. Lancet. 2019;394(10210):1724-1736.

19. Vyas S, Kumaranayake L. Constructing socio-economic status indices: how to use principal components analysis. Health Policy Plan. 2006;21(6):459-468.

20. Bayley N: Bayley Scales of Infant and Toddler Development: Administration Manual, 3rd edition. In. United States of America: Psychorp; 2006.

21. Fernald LCH, Prado EL, Kariger PK, Raikes A. A toolkit for measuring early childhood development in low and middle income countries (English). Washington, D.C.: World Bank Group (2017). Available at: http://documents.worldbank.org/curated/en/384681513101293811/A-toolkit-for-measuring-earlychildhood-development-in-low-and-middle-income-countries

22. Casey PH, Bradley RH, Nelson JY, Whaley SA.. The clinical assessment of a child's social and physical environment during health visits. J Dev Behav Pediatr. 1988;9(6):333-338.

23. Casey PH, Barrett K, Bradley RH, Spiker D. Pediatric clinical assessment of mother-child interaction: concurrent and predictive validity. J Dev Behav Pediatr 1993, 14(5):313-317.

24. Onis M. WHO Child Growth Standards based on length/height, weight and age. Acta Paediatrica 2006;95:76-85 
25. Hosmer DW, Lemeshow S, Sturdivant RX. Applied logistic regression. New York: Wiley; 2013

26. Bursac Z, Gauss $\mathrm{CH}$, Williams DK, Hosmer DW. Purposeful selection of variables in logistic regression. Source Code Biol Med 2008;3:17. doi: 10.1186/1751-0473-3-17.

27. Selvin S. Statistical analysis of epidemiologic data. 3rd Edition, New York: NY: Oxford University Press 1996, 213-214.

28. Wood SN. Generalized Additive Models: An Introduction with R. 2nd ed.: Chapman and Hall/CRC, Taylor and Francis Group; 2017

29. Durand CP. Does raising type 1 error rate improve power to detect interactions in linear regression models? A simulation study. PLoS One. 2013;8(8):e71079

30. Marshall SW. Power for tests of interaction: effect of raising the Type I error rate. Epidemiol Perspect Innov. 2007;4:4

31. McClelland GH, Judd CM. Statistical difficulties of detecting interactions and moderator effects. Psychol Bull. 1993;114(2):376-90

32. Poole C. Low P-values or narrow confidence intervals: which are more durable? Epidemiology. 2001;12(3):291-4.

33. Greenland S, Rothman KJ. Chapter 18: Concepts of Interaction. Modern Epidemiology 2 Edition (Edited by: Rothman KJ, Greenland S). New York NY: Lippincott-Raven 1998, 329-342.

34. World Health Organization, United Nations Children's Fund, World Bank Group. Nurturing care for early childhood development: a framework for helping children survive and thrive to transform health and human potential. Geneva: World Health Organization; 2018. Licence: CC BY-NC-SA 3.0 IGO. Available at: https://apps.who.int/iris/bitstream/handle/10665/272603/9789241514064-eng.pdf? ua $=1$

\section{Figures}
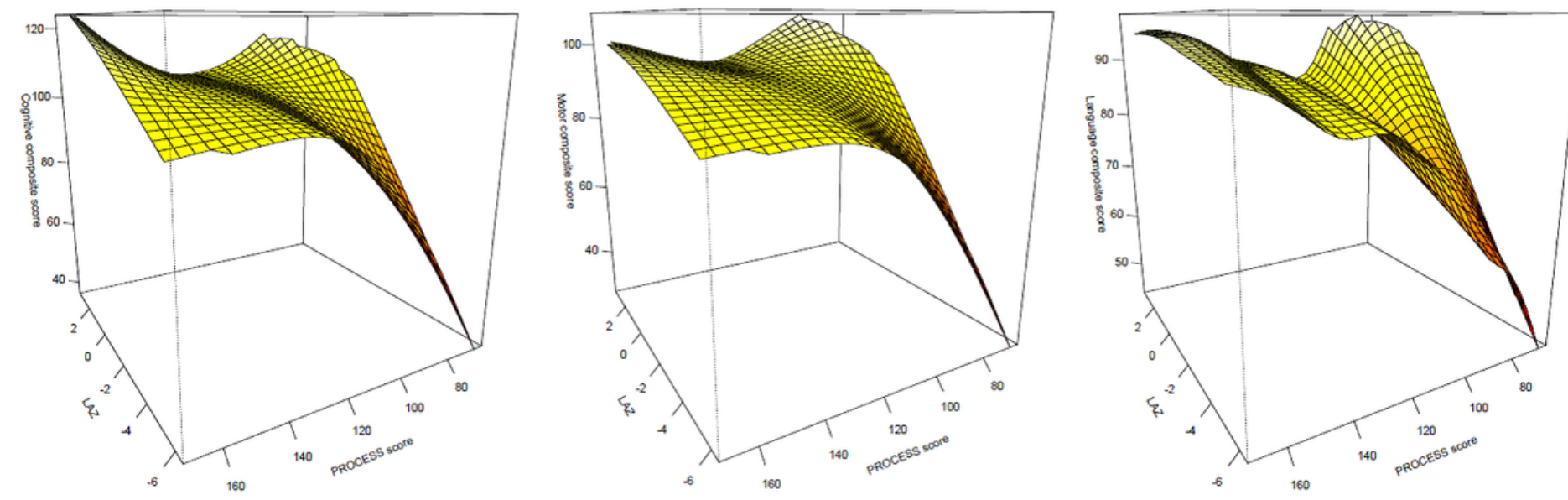

Figure 1 
GAM plot depicting the relationship between length-for-age Z score, PROCESS score and cognitive, motor and language composite score. 